\title{
Future Earth - Research For Global Sustainability
}

THORSTEN KIEFER

PAGES (Past Global Changes) International Project Office, Bern, Switzerland; thorsten.kiefer@pages.unibe.ch

\section{Change is on the way for Global Environmental Change.}

Y ou may have heard some buzz around an initiative called Future Earth. The project, in the works since 2009, will affect all Global Change scientists, and is expected to become operational over the next 1-2 years.

Future Earth is expected to give Global Environmental Change (GEC) science a total makeover, by unifying existing programs and removing disciplinary boundaries, ultimately creating more streamlined communication and cooperation across the broad range of GEC disciplines.

An alliance of several organizations-jointly representing international cooperation, education, and GEC science funding - is behind Future Earth. The program will unify three of the four existing GEC programs, namely the International Human Dimensions Programme (IHDP), DIVERSITAS, and PAGES' parent organization, the International GeosphereBiosphere Programme (IGBP). The fourth GEC program, the World Climate Research Programme (WCRP), will be associated with Future Earth while remaining a separate entity.

The program's full name, "Future Earth- research for global sustainability", indicates that it is more than a mere merger of program themes, however. Future Earth activities will be expected to contribute to finding solutions toward challenges that societies face as a direct or indirect consequence of environmental change. (See Figure 1 for a visual illustration of these goals.)

Achieving this will require lively communication between the producers and users of scientific knowledge, i.e. between scientists and stakeholders. Thus, Future Earth is set to involve not only a broad spectrum of scientists, but also of stakeholders, from policy-makers to those in industry. The idea is to invite stakeholders to co-design research agendas and to even co-produce knowledge. By bringing together natural and social sciences, humanities, economics, and technology development, Future Earth aims at a broadly interdisciplinary and inclusive effort, better suited for effectively tackling interconnected and multifaceted problems.

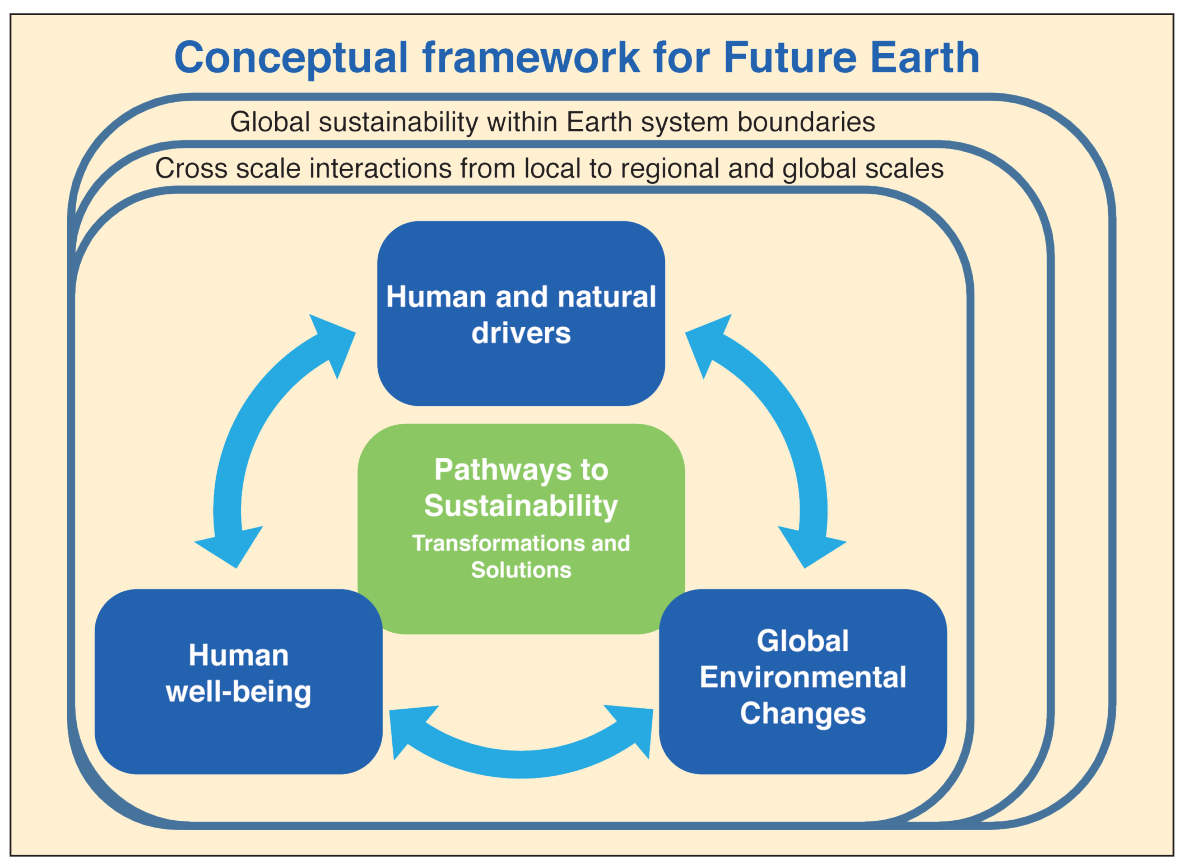

\section{Future Earth at Present}

So far, a task force group (Transition Team) has been set up, which has drafted frameworks for the research and for the structural organization of Future Earth. While still subject to modifications, the current version of the research framework contains three broad themes:

(1) Dynamic Planet: Observing, explaining, understanding, projecting Earth, environmental and societal system trends, drivers and processes and their interactions; anticipating global thresholds and risks.

(2) Global Development: Providing the knowledge for sustainable, secure, and fair stewardship of food, water, biodiversity, health, energy, materials, and other ecosystem functions and services.

(3) Transformation toward Sustainability: Understanding transformation processes and options, assessing how these relate to human values, emerging technologies and economic development pathways, and evaluating strategies for governing and managing the global environment across sectors and scales.

\section{Future Earth and PAGES}

PAGES has provided occasional input to Future Earth's development in several ways. Given that Paleoscience can obviously contribute a lot to Theme 1 , and to some aspects of Theme 2, PAGES has provided the Future Earth Transition Team with two "Past lessons" essays that explain how paleoscience can contribute generally to climatic and environmental themes. These essays can be downloaded from the PAGES website (Products > Other)

Additionally, the PAGES Scientific Steering Committee has put forward several requests to developers of Future Earth: To make sure that existing communities and expertise are maintained, to commit to basic science, to complement disciplinary science with a well-funded platform for interdisciplinary science, to provide professional science communication, and to adopt long-term and historical/geological observations as part of their observation strategy.

The shifting framework of GEC science is prompting associated communities and organizations to revisit their agendas and strategies. For PAGES, the upcoming Open Science Meeting titled "The Past: A Compass for Future Earth" will serve as a platform to discuss the opportunities and challenges Future Earth could bring to paleoscientific research, and how PAGES can help to make best use of the opportunities while mastering the challenges.

This Program News article provides only a brief introduction to Future Earth. For more detailed information, please visit the Future Earth website at: http://www. icsu.org/future-earth. 